\title{
Conceptions in parasite-microbiota relationships
}

\author{
Review Enas A Elsaftawy ${ }^{1,2}$, Rita M Wassef ${ }^{3}$ \\ Article \\ Departments of Medical Parasitology, Faculty of Medicine, Cairo University ${ }^{1}$, Armed \\ Forces College of Medicine ${ }^{2}$, Helwan University ${ }^{3}$, Cairo, Egypt
}

\begin{abstract}
Abundant information refers to the role of microbiota in maintaining homeostasis by assisting, improving, and regulating immunity in humans. Yet, the effect exerted by parasitic infections on the developing microbiota, is so far not recognized. Various parasites were related to specific alterations in the essential loads of developing microbiota. Additionally, modulation of immune functions was reported. This review aimed to present examples for the interaction between parasitic infections and microbial gut imbalance dubbed dysbiosis. This form of parasite-microbiota interaction seems to influence both the metabolism and the acquired immunity of the host. Consideration of this data will direct future studies to focus on the altered microbiota during various parasitic infections and to highlight the benefits of its re-enrichment in the therapeutic trials.
\end{abstract}

Keywords: dysbiosis; flora; luminal parasites; microbiota; probiotics

Received: 28 March, 2021, Accepted: 12 August, 2021.

Corresponding Author: Rita M Wassef, Tel.: +20 1005782994, E-mail: rita.wassef@med.helwan.edu.eg

Print ISSN: 1687-7942, Online ISSN: 2090-2646, Vol. 14, No. 2, August, 2021.

\section{INTRODUCTION}

Parasites are organisms that depend on their hosts, and typically in a parasitic relationship, one organism flourishes and proliferates at the expense of the other. Research on the normal microbiome communities during parasitic infections showed that the definition of 'intestinal parasitosis' requires re-assessment. It was postulated that intestinal dysbiosis as a state of disease induced by a parasite, is distinctive from the term intestinal parasitosis ${ }^{[1,2]}$.

The word 'microbiota' is composed of two syllables; 'micro' that refers to the invisible size, and 'biota' which is the bacterial ecosystem that inhabits a specific site in the host. This microbiota plays a crucial role in early life to establish the immune system in health and disease $\mathrm{e}^{[3-5]}$. During early life, a stable gut microbiome is completed by the age of 31 months ${ }^{[6,7]}$; and its balance continues to be crucial for the longterm well-being and health ${ }^{[8,9]}$. Elwakil ${ }^{[1]}$ suggested that intimate factors and pathways governing the relationships between host, microbiota, and parasites are multifaceted. Although in several cases, the relation is not fully defined, a recent review has supported the role of microbiota in remedying the host immature immune system ${ }^{[10]}$.

Dysbiosis due to bacterial destabilization has been associated with several diseases. For instance, recent studies revealed alterations in intestinal bowel diseases ${ }^{[11,12]}$. Additionally, a recent study conducted by Ramírez-Carrillo et al. ${ }^{[13]}$ related the incidence of depression to the disturbance in the networks of the gut microbiota by Ascaris lumbricoides. However, modulation of this microbiota through consumption of live bacteria (probiotics), or non-digestible elements has been speculated in the inhibition or even treatment of some conditions ${ }^{[14]}$. The current review aimed to characterize some figures of alterations in microbiota associated with various parasitic infections.

\section{[I] Intracellular parasites}

(1) Toxoplasma gondii is an intracellular sporozoa that can cause infection in any nucleated cell. Toxoplasmosis has been shown to induce massive necrosis and extensive pathology in the distal intestinal mucosa and villi in murine models. These pathological changes were attributed to bacterial dysbiosis besides immune factors such as the CD-4 T cells and interferon gamma (IFN- $\gamma$ ) cytokine ${ }^{[15]}$. Dysbiosis had been proposed to be dependent on the destabilization of the intestinal barrier either by the lytic replication of the parasite or from the toxic by-products of the host immune reactions, such as nitrogen intermediates or reactive oxygen species. For instance, production of IFN- $\gamma$ during toxoplasmosis leads to loss of Paneth cells resulting in reduced levels of the antimicrobial peptides and dysbiosis ${ }^{[16,17]}$ dominated chiefly by Enterobacteriaceae $^{[14]}$. In fact, the induced IFN- $\gamma /$ signal transducer and activator of transcription-1/ inducible nitric oxide synthase (IFN- $\gamma /$ STAT-1/iNOS) axis, was described as crucial for parasite resistance $^{[18]}$. It was assumed to provide a pool of nitrate that acts as a source for anaerobic respiration and promotes overgrowth of Enterobacteriaceae.

Similarly, in experimentally induced colitis using dextran sulphate sodium (DSS), host-derived nitrate was found to directly promote the flush of Enterobacteriaceae bacteria in the colon ${ }^{[19]}$. This proves that local inflammation in the large intestine causes upgrade of the respiratory electron acceptors 
levels like $\mathrm{N}$ oxides and $\mathrm{S}$ oxides, that act as a substrate for the expansion of facultative anaerobic bacteria ${ }^{[20]}$. Hatter et $a .^{[15]}$ noted an ominous outgrowth of Clostridia spp. that was sustained in chronic infection with toxoplasmosis. Also, Egan et al. ${ }^{[1]}$ suggested that the depletion of gut flora reduces mice resistance to $T$. gondii-triggered ileitis. Likewise, Couturier-Maillard et $a .^{[22]}$ suggested that the collaboration between intestinal commensals and T. gondii in the development of small intestine inflammation increases the capability of the parasite to approach the epithelial cells and promotes its invasion to the mucosa.

(2) Cryptosporidium parvum is another intracellular intestinal sporozoa that has been hypothesized to trigger dysbiosis indirectly by causing damage to the intestinal epithelium $^{[23]}$. Fecal microbiota from mice infected with $C$. parvum were shown to differ significantly from that of non-infected controls. Amazingly, a recent study demonstrated that probiotics can significantly influence the intestinal microenvironment and the epithelial lining which promotes the proliferation of $C$. parvum $^{[24]}$.

(3) Leishmaniasis is caused by intracellular flagellates that were shown to trigger skin dysbiosis in humans and murine models. Cutaneous leishmaniasis is characterized by augmented Staphylococcus and/ or Streptococcus infections and skin inflammation. Interestingly, in murine models this dysbiosis was found to be transferable to naive mice ${ }^{[25]}$. Similarly, visceral leishmaniasis (VL) patients are more susceptible to fatal nosocomial secondary bacterial infections (Pseudomonas aeruginosa and Staphylococcus aureus) ${ }^{[26]}$. This was attributed to the suppressed status of T-helper 1 due to alterations in antigen presentation, MHC/HLA, antigen processing, $\mathrm{T}$ cell receptor recognition, and the myeloid derived suppressor cells ${ }^{[27-29]}$. However, establishment of VL infection in murine models with previously induced intestinal dysbiosis showed late onset and development of weight $\operatorname{loss}^{[30]}$.

\section{[II] Luminal (intestinal and genitourinary) parasites}

(1) Giardia duodenalis (G. Iamblia) is an intestinal flagellate that inspires dysbiosis by overwhelming the physical mucus and epithelial barrier by several mechanisms. The trophozoite stage of the parasite is extremely motile via its flagella ${ }^{[31]}$ and possesses proteolytic activity that disrupts the integrity of mucin-2 (MUC2) to yield a less viscous physical barrier ${ }^{[32-34]}$. In addition, it produces secretory/excretory cysteine proteases $(\mathrm{CP})^{[35]}\left(\mathrm{CP} 2, \mathrm{CP} 3\right.$, and CP16160 ${ }^{[32,36]}$ ) that cause apoptosis of the epithelial lining of the intestine and disruption of the tight junctions ${ }^{[37]}$. Giardipain- 1 is another virulent factor with proteolytic activity similar to cathepsin B-like protein. It induces the formation of pore-like defects and membrane blebs, reduces the trans-epithelial electrical resistance, and targets mainly the tight junction proteins (occludin and claudin-1). In addition, it stimulates the activation of caspase-3, the fragmentation of poly ADP ribose polymerase (PARP), and the exposure of phosphatidylserine causing apoptosis of the epithelial cells ${ }^{[38]}$. Consequently, the mucosal microbiota adjacent to the epithelial cells can penetrate the thin lining of the host-derived glycans, the cell surface glycocalyx and the extracellular secreted mucu ${ }^{[39]}$. The pathogenic dysbiotic microbiota associated with giardiasis in germ free mice, induces the signalling pathway of the toll-like receptor- 4 , and the production of the pro-inflammatory cytokine IL$1 \beta^{[37]}$.

Gerbaba et al. ${ }^{[40]}$ showed that G. lamblia induces functional alterations in the commensal microbiota, possibly transforming them into opportunistic pathogens, and altering the host-microbe homeostatic interactions. Interestingly, Allain et al. ${ }^{[32]}$ demonstrated that the high proteolytic activity by $G$. lamblia is protective to the host against concurrent bacterial entero-pathogens by promoting bacterial killing and alleviating inflammation of the intestine. Bartelt et al. ${ }^{[1]}$ assumed that in association with protein malnutrition the intestinal microbiota promoted persistent colonization by G. lamblia that led to growth impairment in experimentally infected mice.

(2) Blastocystis spp. are the most common eukaryotic intestinal protozoa in human ${ }^{[42]}$. As an anaerobe, it lacks several definitive mitochondrial features and misses the standard mitochondrial electron transport chain and oxidative phosphorylation ${ }^{[43]}$. Notably in a healthy gut, oxygen concentration is extremely low ${ }^{[44]}$ to promote the growth of obligate anaerobic microbiota from the Bacteroides and Firmicutes phyla ${ }^{[45]}$. In a dysbiotic gut, when the intestinal microbiota get disrupted and luminal bioavailability of oxygen increases, the resulting alteration in intestinal biodiversity promotes the growth of the facultative anaerobic Enterobacteriaceae ${ }^{[12,46,47]}$. A strict anaerobe such as Blastocystis spp. cannot sustain itself in this medium that is not its ideal ecosystem. In this context, in a well-established irritable bowel syndrome (IBS), dysbiosis Blastocystis spp. may be compelled out of the gut since the early stages of the disease $\mathrm{e}^{[48]}$.

On the other hand, Tsaousis et al. ${ }^{[49]}$ suggested that Blastocystis spp. has an alternative oxidase nature that allows it to deal with fluctuating oxygen concentrations in the gut and should be better termed as a microaerophilic. Blastocystis infection in rats involved colon hypersensitivity and showed alterations in the composition of the microbiota and hence their metabolic shifts ${ }^{[50]}$.

Conversely, two studies ${ }^{[51,52]}$ reported the presence of healthy microbiota rather than dysbiosis in patients infected with Blastocystis spp. Moreover, Scanlan et al. ${ }^{[53]}$ considered Blastocystis spp. a member of the 
healthy microbiota. However, in a previous study the genotype of the parasite appeared to play a hidden role in the capability of the parasite in contributing to disease ${ }^{[54]}$. In this context, the relationship between different genotypes of the parasite and dysbiosis seems to be a new point of research.

(3) Entamoeba histolytica was previously shown to modify the tight junction proteins and disturb the permeability of the epithelial barrier, allowing translocation of intestinal microbiota into the mucosal surfaces and spread to the other organs ${ }^{[55,56]}$. Iyer et $a l^{[57]}$ reported that E. histolytica favours the phagocytosis of bacterial species such as Lactobacillus ruminus. Similarly, Verma et al. ${ }^{[58]}$ revealed that $E$. histolytica associated dysbiosis was characterized by increased Bifidobacterium spp. in faecal samples, while other bacteria that are essential for the maintenance of intestinal homeostasis such as Bacteroides, Clostridia, Campylobacter, Lactobacillus, and Eubacterium were reduced as compared to healthy subjects. Interestingly, Sicard et al. ${ }^{[59]}$ demonstrated that colonic microbiota break down complex carbohydrates into glycans that can act as a nutrient source for E. histolytica. With the absence of bacteria, E. histolytica is forced to be in close contact with the epithelium to feed and search for alternative sources of energy in the lumen ${ }^{[60]}$. Moreover, in germ free mice the MUC2 layer was found to be thinner and penetrable ${ }^{[59]}$ with diminutive O-glycan monomers ${ }^{[52]}$.

Additionally, it was postulated that the ratio of bacterial phyla present in the host microbiota may alter or influence the colonization of $E$. histolytica. For instance, Escherichia coli was found to protect $E$. histolytica against oxidative stress in two patterns ${ }^{[61]}$ described in figure (1). However, in murine models Clostridium is defensive during E. histolytica infection through the increased production of interleukin 17A, dendritic cells, and neutrophils. Moreover, bone marrow-derived dendritic cells were reported to secrete elevated levels of IL-23 ${ }^{[62]}$. Gilchrist et al. ${ }^{[63]}$ showed that the expansion of Prevotella copri probiotic was associated with dysentery due to intestinal amoebiasis in infants from 600 to 800 days of age. Sarjapuram et $a l^{[64]}$ revealed that probiotics (specifically Lactobacillus casei) have an anti-proliferative effect on E. histolytica. Varet et al. $^{[61]}$ speculated this effect to be unrelated to alterations in the $\mathrm{pH}$ value of the media.

(4) Trichuris trichiura is a round worm reported in a Malaysian study to be associated with shifts in the composition of the gut microbiota of infected patients especially with Paraprevotellaceae bacteria concerned with the breakdown of proteins and carbohydrates in food $^{[65]}$. In general, helminthic infections may promote regulatory immune cell reactions that may suppress harmful allergic and inflammatory diseases. They are supposed to elicit regulatory $\mathrm{T}$ cells by altering the gut microbiota or via secretion of bioactive molecules. Hence, worms and their secretory molecules may be innovative treatments for allergic inflammation ${ }^{[1,66]}$.

(5) Trichomonas vaginalis is a flagellate that causes the most common sexually transmitted disease (STD) during the child bearing period in female patients ${ }^{[67]}$. In fact, trichomoniasis was shown to pave the way for bacterial dysbiosis owing to multiple virulence factors. This protozoon employs its cytopathic effect through the release of pore-forming proteins active at $\mathrm{pH} 5.8^{[68]}$ Garber et al. ${ }^{[69]}$ isolated a specific soluble heat and acid labile cell-detaching factor from cultured T. vaginalis that possesses trypsin like action and can disrupt the monolayer cells at optimum $\mathrm{pH}$ 6.5. In another experimentally infected murine model, $\beta$-hemolysin was reported to be another virulence factor ${ }^{[70]}$ that destructs the carbohydrate cell monolayers and was found to produce subcutaneous abscesses ${ }^{[71]}$. Invasion of the mucous layer entails efficient motility by the parasites and the production of adhesins and mucinases $^{[72]}$. Additionally, to thrive the antibody response, it produces several cysteine proteinases that degrade $\operatorname{IgG}$, IgM, and $\operatorname{Ig} \mathrm{A}^{[73]}$.

Increased T. vaginalis colonization was associated with the bacterial Gardenella vaginalis species that cause bacterial vaginosis at the expense of the commensal Lactobacillus spp. ${ }^{[74]}$. This was attributed to the efficient

Escherichia coli live bacteria protects $E$. histolytica against oxidation by two patterns of mechanisms

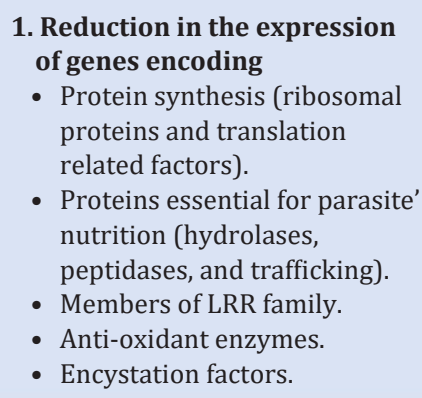

1. Reduction in the expression of genes encoding

- Protein synthesis (ribosomal proteins and translation related factors).

- Proteins essential for parasite nutrition (hydrolases, peptidases, and trafficking).

- Members of LRR family.

- Anti-oxidant enzymes.

- Encystation factors.

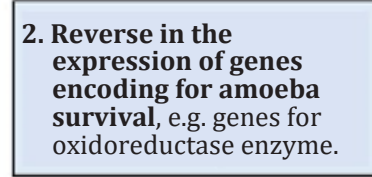

Fig. 1. Paradigm of Escherichia coli/E. histolytica interaction. LRR: Leucinerich repeat family genes. Illustrated by E. Elsaftawy. 
phagocytic action of the parasite by killing and ingesting lactobacilli ${ }^{[75]}$. Diminution in lactobacilli populations upgrades the vaginal $\mathrm{pH}$ that is normally fluctuating between 2.8 and $4.2^{[76]}$ creating a milieu more promising for the proliferation of dysbiotic bacteria. Subsequently, the biofilm of the dysbiotic bacteria was found to provide adhesion for $T$. vaginalis ${ }^{[78]}$. Also, dysbiotic bacteria refine the cytoadhesion of the parasite to the vaginal cells and mucins. Gardnerella vaginalis is the most associating dysbiotic bacterium; however other genera, such as Atopobium vaginae, Prevotella bivia, Bacteroides, and Mycoplasma hominis can also flourish ${ }^{[67,73,78,79]}$.

\section{[III] Blood flukes (Schistosoma spp.)}

S. haematobium is a urinary blood fluke (trematode) that inhabits the vesical plexus around the bladder. It has been related to a shift in the structure of the faecal microbiome community ${ }^{[80-82]}$, in the form of reduced phylum Firmicutes bacteria and prevalence of phylum Proteobacteria bacteria. A number of alterations were also detected including reductions in Clostridiales family bacteria and surges in Moraxellaceae, Veillonellaceae, Pasteurellaceae, and Desulfovibrionaceae ${ }^{[81]}$. Enhancement of urease enzyme has been related to dysbiosis and inflammation. Owing to the habitat of the parasite in the vasculatures around the urinary bladder the indirect link between systemic immunity and microbiota can be suggested as a point of research ${ }^{[81]}$.

S. mansoni is another blood fluke that inhabits the inferior mesenteric plexus of veins draining the colon. Using murine models, a partial relationship was proposed between the parasitic infection and changes in the configuration of the host microbiome ${ }^{[83]}$. Variances in the gut microbial paradigm involved enrichment in Proteobacteria phylum and the deficiency of the immunoregulatory bacteria (e.g. Lactobacillus). This disruption in the gut microbiota was directly associated with higher worm and egg burden, together with amplified immune responses to Schistosoma antigens ${ }^{[84]}$. Interestingly, higher abundance of Fusobacterium spp. was found to be accompanied with increased efficacy of praziquantel ${ }^{[85]}$. On the other hand, Jenkins et al. ${ }^{[83]}$ and Schneeberger et al. ${ }^{[85]}$ proposed that neither $S$. mansoni infection nor praziquantel administration promotes a significant alteration in the composition of gut microbiota.

Another interesting finding was published by Floudas et al. ${ }^{[86]}$ who reported less susceptibility to induced colitis in mice infected with adult male $S$. mansoni as compared to infection with adult male and female worms. This was assumed to be related to the capability of the male worms to regulate the host's immune reactions and overcomes colitis through restricting gut dysbiosis.

\section{[IV] Skin parasites}

Sarcoptes scabiei is a mite that causes skin infestation and is thought to promote bacterial infections by breaching the skin barrier. It incapacitates the expression of many adhesion molecules of the epidermal cells, the endothelial cells and the dermal fibroblasts ${ }^{[87-89]}$. This is achieved by secretion of protease enzymes to facilitate tissue invasion and migration ${ }^{[90]}$. It evades immunity through the excretion of uncharacterized immune modulatory molecules ${ }^{[91]}$ and complement inhibitors that are supposed to assist the propagation of Streptococcus pyogenes ${ }^{[92]}$. Moreover, it induces itching due to allergy and inflammatory responses against the arthropod and its secretory/excretory metabolic by-products that pave the way for bacterial infections. Abreu-Velez et al. ${ }^{[93]}$ assumed that itching sensation may be aggravated as an auto-reactivity to sweat glands and nerves in close proximity to the sites of infestation.

Disruption of the skin barrier facilitates the invasion of opportunistic pathogens and permits secondary bacterial infection, most frequently by Staphylococcus aureus and S. pyogenes that belongs to group A Streptococci (GAS). These bacteria have been isolated from skin tunnels and faecal by products of the mite suggesting that the arthropod could contribute directly to the dissemination of the bacteria and increase risk of impetigo ${ }^{[94,95]}$. Moreover, Swe et al. ${ }^{[96]}$ using a porcine model, assumed that scabies mites shift the growth of the skin microbiota from the commensal Staphylococcus hominis to Staphylococcus chromogenes. Further sequel of skin dysbiota is the real possibility of renal glomerular damage due to streptococcal infection that may occur many years afterwards ${ }^{[97]}$ (Figure 2). Another study showed that control of scabies with ivermectin is also related to significant lower isolations of streptococci from skin lesions and haematuria ${ }^{[98]}$.

\section{CONCLUDING REMARKS}

1. It is currently accepted that the gut microbiota interrelate with human health and that its disruption by a parasite has a hidden effect in the progression of the parasitic disease.

2. The real effect of dysbiosis in many parasitic diseases is still not clear and necessitates further research.

3. The current recommendations for probiotic therapies in parasitic diseases are still limited and requires further large cohorts' studies to determine the right probiotic strain for a given parasitic strain.

4. Parasites alter microbiota through different mechanism, as proposed in the following parasites:

- T. gondii: Destabilization of the intestinal barrier, and increased production of nitrates.

- Cryptosporidium spp: Damage to the intestinal epithelium.

- Leishmania spp.: Alterations in antigen presentation, MHC/HLA, and antigen processing, disruption of the $\mathrm{T}$ cell receptor recognition, as well as modification in the myeloid derived suppressor cells.

-G. Iamblia: Disruption of the integrity of MUC2, reduction of the viscous physical barrier, and degradation of tight junction proteins and apoptosis 


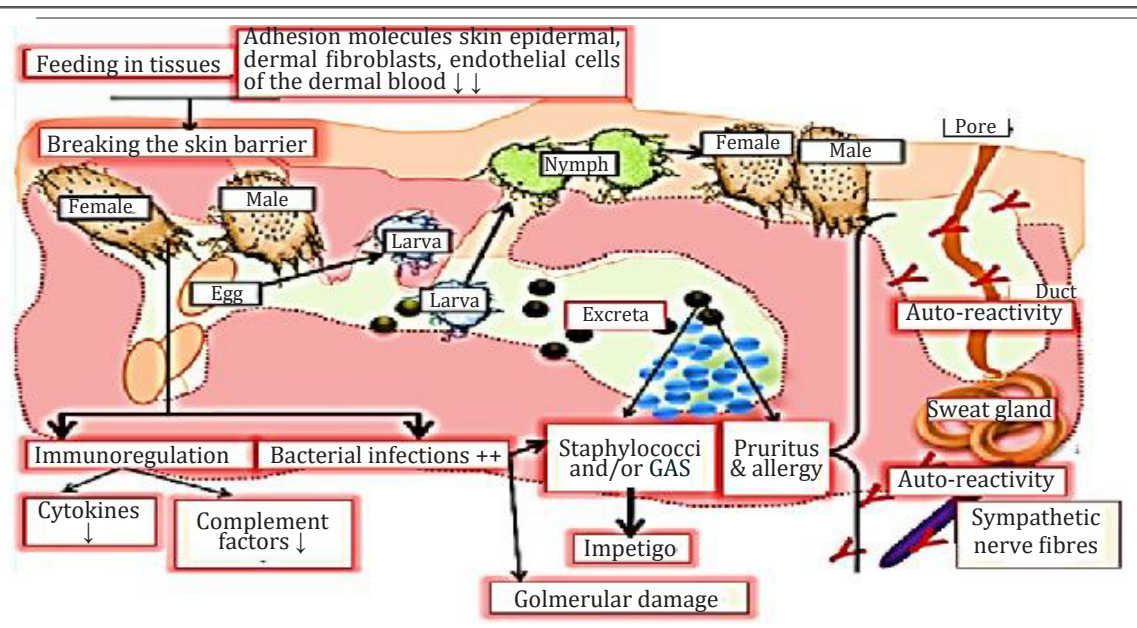

Fig. 2. Dysbiosis in scabies infection. GAS: Group A streptococci. Illustrated by E. Elsaftawy.

of the intestinal epithelial cells utilizing secretoryexcretory cysteine proteases.

- Blastocystis spp.: Colon hypersensitivity, alterations of microbiota composition, and metabolic shifts of the intestinal microbiota

- E. histolytica: Several mechanisms were proposed: modification of goblet cell, reduction of mucus assembly (germ free murine models), modification of tight junction proteins, distortion of epithelial barrier permeability, translocation of intestinal mirobiota into mucosal surfaces, dissemination of microbiota to other organs, gene regulation and altered expression of the leucine-rich repeat (LRR) family genes (documented with enteric bacteria but not with probiotics), phagocytosis of beneficial bacteria, and increased Bifidobacterium species .

- T. trichura: Promotion of regulatory immune cell reactions, and secretion of bioactive molecules.

- T. vaginalis: Interaction with urogenital epithelium, B-hemolytic and mucinase activities, increasing $\mathrm{pH}$ for optimal activity of cell-detaching factor and pore-forming proteins, degradation of $\operatorname{IgG}$, IgM, IgA, and phagocytosis of beneficial bacteria.

- Schistosoma spp.: Enhancement of urease enzyme, immunomodulation, and alterations of microbiota composition.

-S. scabiei: Breach skin barrier was proposed through skin scratching (auto reactivity), and protease enzymes. Besides, immunomodulation and inhibition of the adhesion molecules were reported.

Authors' contribution: Both authors contributed substantially to the manuscript. Elsaftawy EA conceptualised the idea, wrote the initial draft, and drew all the figures. Wassef RM supported the idea, revised and edited the manuscript, and took correspondence responsibility. Both authors agreed on the final version submitted to the chosen journal and approved revision in response to reviewers' comments.

Declarations of interest: The authors declared that there were no potential conflicts of interest concerning the research, authorship, and/or publication of this article.
Financial support: This work did not receive any financial fund from any organization or institution.

\section{REFERENCES}

1. Elwakil H. Parasites and microbiota: A complex relationship. PUJ 2018; 11(3): 122-124.

2. Guseynova N, Mamedova S. Influence of parasitosis on the immune system of the body and on intestinal dysbiosis. AIJR Abstracts 2020, 36.

3. Round JL and Mazmanian SK. The gut microbiota shapes intestinal immune responses during health and disease. Nat Rev Immunol 2009; 9: 313-323.

4. Sekirov I, Russell SL, Antunes LC, Finlay BB. Gut microbiota in health and disease. Physiol Rev 2010;90: 859-904.

5. Gensollen T, Iyer SS, Kasper DL, Blumberg RS. How colonization by microbiota in early life shapes the immune system. Science 2016; 352: 539-544.

6. Bäckhed F, Roswall J, Peng Y, Feng Q, Jia H, KovatchevaDatchary P, et al. Dynamics and stabilization of the human gut microbiome during the first year of life. Cell Host Microbe 2015; 17(5):690-703.

7. Stewart CJ, Ajami NJ, O'Brien JL, Hutchinson DS, Smith DP, Wong MC, et al. Temporal development of the gut microbiome in early childhood from the TEDDY study. Nature 2018; 562: 583-588.

8. Iizumi T, Battaglia T, Ruiz V, Perez Perez GI. Gut microbiome and antibiotics. Arch Med Res 2017; 48: 727-734.

9. Dong TS, Gupta A. Influence of early life, diet, and the environment on the microbiome. Clin Gastroenterol Hepatol 2018; 17: 231-242.

10. Ahern PP, Maloy KJ. Understanding immune-microbiota interactions in the intestine. Immunology 2020; 159(1): 4-14.

11. Kassinen A, Krogius-Kurikka L, Mäkivuokko H, Rinttilä T, Paulin L, Corander J, et al. The faecal microbiota of irritable bowel syndrome patients differs significantly from that of healthy subjects. Gastroenterol 2007; 133(1):24-33.

12. Rigottier-Gois L. Dysbiosis in inflammatory bowel diseases: the oxygen hypothesis. ISME J 2013; 7:12561261.

13. Ramírez-Carrillo E, Gaona O, Nieto J, Sánchez-Quinto A, Cerqueda-García D, Falcón L I, et al. Disturbance in human 
gut microbiota networks by parasites and its implications in the incidence of depression. Sci Rep 2020; 10(1): 1-12.

14. Connolly E, Abrahamsson T, Bjorksten B. Safety of D (-)-lactic acid producing bacteria in the human infant. J Pediatr Gastroenterol Nutr 2005; 41: 489-492.

15. Hatter JA, Kouche YM, Melchor SJ, Ng K, Bouley DM, Boothroyd JC, et al. Toxoplasma gondii infection triggers chronic cachexia and sustained commensal dysbiosis in mice. PloS one 2018; 13(10): e0204895.

16. Raetz M, Hwang S-H, Wilhelm CL, Kirkland D, Benson A, Sturge CR, et al. Parasite-induced TH1 cells and intestinal dysbiosis cooperate in IFN- $\gamma$-dependent elimination of Paneth cells. Nat Immunol 2013; 14:136-142.

17. Burger E, Araujo A, López-Yglesias A, Rajala MW, Geng L, Levine B, et al. Loss of Paneth cell autophagy causes acute susceptibility to Toxoplasma gondii-mediated inflammation. Cell Host Microbe 2018; 23:177-190.

18. Wang S, El-Fahmawi A, Christian DA, Fang Q Radaelli $\mathrm{E}$, Chen $\mathrm{L}$, et al. Infection-induced intestinal dysbiosis is mediated by macrophage activation and nitrate production. Mbio 2019; 10(3): e00935-19.

19. Winter SE, Winter MG, Xavier MN, Thiennimitr P, Poon V, Keestra AM, et al. Host-derived nitrate boosts growth of E. coli in the inflamed gut. Science 2013; 339 (6120):708711.

20. Winter SE, Lopez CA, Bäumler AJ. The dynamics of gutassociated microbial communities during inflammation. EMBO Rep 2013; 14(4):319-327.

21. Egan CE, Cohen SB, Denkers EY. Insights into inflammatory bowel disease using Toxoplasma gondii as an infectious trigger. Immunol Cell Biol 2012; 90(7):668-675.

22. Couturier-Maillard A, Froux N, Piotet-Morin J, Michaudel C, Brault L, Le Bérichel J, et al. Interleukin-22-deficiency and microbiota contribute to the exacerbation of Toxoplasma gondii-induced intestinal inflammation. Mucosal immunology 2018; 11(4):1181-1190.

23. Ras R, Huynh K, Desoky E, Badawy A, Widmer G. Perturbation of the intestinal microbiota of mice infected with Cryptosporidium parvum. Int J Parasitol 2015; 45(8):567-573.

24. Oliveira BCM, Widmer G. Probiotic product enhances susceptibility of mice to cryptosporidiosis. Appl Environ Microbiol 2018; 84(21): e01408-18.

25. Gimblet C, Meisel JS, Loesche MA, Cole SD, Horwinski J, Novais FO, et al. Cutaneous leishmaniasis induces a transmissible dysbiotic skin microbiota that promotes skin inflammation. Cell Host Microbe 2017; 22(1):13-24.

26. Andrade TM, Carvalho EM, Rocha H. Bacterial infections in patients with visceral leishmaniasis. J Infect Dis 1990; 162(6):1354-1359.

27. Chang KP. Leishmania donovani-macrophage binding mediated by surface glycoproteins/antigens: characterization in vitro by a radioisotopic assay. Mol Biochem Parasitol 1981; 4: 67-76.

28. Wilson ME, Pearson RD. Roles of CR3 and mannose receptors in the attachment and ingestion of Leishmania donovani by human mononuclear phagocytes. Infect Immun 1988; 56: 363-369.

29. Saha B, Das G, Vohra H, Ganguly NK, Mishra GC. Macrophage-T cell interaction in experimental visceral leishmaniasis: failure to express costimulatory molecules on Leishmania-infected macrophages and its implication in the suppression of cell-mediated immunity. Eur J Immunol 1995; 25: 2492-2498.

30. Lewis MD, Paun A, Romano A, Langston H, Langner CA, Moore IN, et al. Fatal progression of experimental visceral leishmaniasis is associated with intestinal parasitism and secondary infection by commensal bacteria and is delayed by antibiotic prophylaxis. PLoS Pathog 2020; 16(4): e1008456

31. Paget TA, James SL. The mucolytic activity of polyamines and mucosal invasion. Biochem Soc Trans 1994; 22(4):394S.

32. Allain T, Fekete E, Buret AG. Giardia cysteine proteases: The teeth behind the smile. Trends Parasitol 2019; 35(8):636-648.

33. Cotton JA, Amat CB, Buret AG. Disruptions of host immunity and inflammation by Giardia duodenalis: potential consequences for co-infections in the gastrointestinal tract. Pathogens 2015; 4(4):764-792.

34. Amat CB, Motta J-P, Chadee K, Buret AG. Giardia duodenalis directly depletes mucins in intestinal goblet cells. FASEB 2016; 30 (1 Supplement): 162.161.

35. Halliez MC, Motta JP, Feener TD, Guérin G, LeGoff L, François A, et al. Giardia duodenalis induces paracellular bacterial translocation and causes postinfectious visceral hypersensitivity. Am J Physiol Gastrointest Liver Physiol 2016; 310(8): G574-G585.

36. Buret AG, Amat CB, Manko A, Beatty JK, Halliez MC, Bhargava A, et al. Giardia duodenalis: new research developments in pathophysiology, pathogenesis, and virulence factors. Curr Trop Med Rep 2015; 2(3):110-118

37. Beatty JK, Akierman SV, Motta JP, Muise S, Workentine ML, Harrison JJ, et al. Giardia duodenalis induces pathogenic dysbiosis of human intestinal microbiota biofilms. Int J Parasitol 2017; 47(6):311-326.

38. Ortega-Pierres G, Argüello-García R, Laredo-Cisneros MS, Fonseca-Linán $\mathrm{R}$, Gómez-Mondragón $\mathrm{M}$, Inzunza-Arroyo $\mathrm{R}$, et al. Giardipain-1, a protease secreted by Giardia duodenalis trophozoites, causes junctional, barrier and apoptotic damage in epithelial cell monolayers. Int J Parasitol 2018; 48(8):621-639.

39. Ouwerkerk JP, De Vos WM, Belzer C. Glycobiome: bacteria and mucus at the epithelial interface. Best Pract Res Clin Gastroenterol 2013; 27(1):25-38.

40. Gerbaba TK, Gupta P, Rioux K, Hansen D, Buret AG. Giardia duodenalis-induced alterations of commensal bacteria kill Caenorhabditis elegans: A new model to study microbialmicrobial interactions in the gut. Am J Physiol Gastrointest Liver Physiol 2015; 308(6):G550-G561.

41. Bartelt LA, Bolick DT, Mayneris-Perxachs J, Kolling GL, Medlock GL, Zaenker EI, et al. Cross-modulation of pathogen-specific pathways enhances malnutrition during enteric co-infection with Giardia lamblia and entero-aggregative Escherichia coli. PLoS Pathog 2017; 13(7): e1006471.

42. El Safadi D, Gaayeb L, Meloni D, Cian A, Poirier P, Wawrzyniak I, et al. Children of Senegal River Basin show the highest prevalence of Blastocystis sp. ever observed worldwide. BMC Infect Dis 2014; 14:164. 
43. Van der Giezen M. Mitochondria and the rise of eukaryotes. BioSci 2011; 61, 594-601.

44. Albenberg L, Esipova TV, Judge CP, Bittinger K, Chen $\mathrm{J}$, Laughlin A, et al. Correlation between intraluminal oxygen gradient and radial partitioning of intestinal microbiota. Gastroenterol 2014; 147: 1055-1063.

45. Donaldson GP, Lee SM, Mazmanian SK. Gut biogeography of the bacterial microbiota. Nat Rev Microbiol 2016; 14(1): 20-32.

46. Byndloss M X, Olsan EE, Rivera-Chávez F, Tiffany CR, Cevallos SA, Lokken KL, et al. Microbiota-activated PPARgamma signaling inhibits dysbiotic Enterobacteriaceae expansion. Science 2017; 357: 570-575.

47. Rivera-Chávez F, Lopez CA, Bäumler AJ. Oxygen as a driver of gut dysbiosis. Free Rad Biol Med 2017; 105: 93-101.

48. Stensvold CR, van der Giezen M. Associations between gut microbiota and common luminal intestinal parasites. Trends Parasitol 2018; 34(5):369-377.

49. Tsaousis AD, Hamblin KA, Elliott CR, Young L, RosellHidalgo A, Gourlay CW, et al. The human gut colonizer Blastocystis respires using Complex II and alternative oxidase to buffer transient oxygen fluctuations in the gut. Front Cell Infect Microbiol 2018; 8:371.

50. Defaye M, Nourrisson C, Baudu E, Lashermes A, Meynier M, Meleine M, et al. Faecal dysbiosis associated with colonic hypersensitivity and behavioural alterations in chronically Blastocystis-infected rats. Sci Rep 2020;10(1):1-2.

51. Audebert C, Even G, Cian A, Loywick A, Merlin S, Viscogliosi E, et al. Colonization with the enteric protozoa Blastocystis is associated with increased diversity of human gut bacterial microbiota. Sci Rep 2016; 6(1): 1-11.

52. Nagel R, Traub RJ, Allcock RJ, Kwan MM, BielefeldtOhmann H. Comparison of faecal microbiota in Blastocystis-positive and Blastocystis-negative irritable bowel syndrome patients. Microbiome 2016; 4(1): 1-9.

53. Scanlan PD, Stensvold CR, Rajilić-Stojanović M, Heilig HG, De Vos W M, O'Toole PW, et al. The microbial eukaryote Blastocystis is a prevalent and diverse member of the healthy human gut microbiota. FEMS microbiology ecology 2014; 90(1): 326-330.

54. El Saftawy EA, Amin NM, Hamed DH, Elkazazz A, Adel S. The hidden impact of different Blastocystis genotypes on C-3 and IgE serum levels: a matter of debate in asthmatic Egyptian children. J Parasit Dis 2019;43(3):443-451.

55. Kissoon-Singh V, Moreau F, Trusevych E, Chadee K. Entamoeba histolytica exacerbates epithelial tight junction permeability and proinflammatory responses in Muc2 $^{-/-}$mice. Am J Pathol 2013; 182(3):852-865.

56. Leon-Coria A, Kumar M, Moreau F, Kris C. Defining cooperative roles for colonic microbiota and Muc2 mucin in mediating innate host defence against Entamoeba histolytica. PLoS Pathog 2018; 14 (11):1-22.

57. Iyer LR, Verma AK, Paul J, Bhattacharya A. Phagocytosis of gut bacteria by Entamoeba histolytica. Front Cell Infect Microbiol 2019; 9: 34.

58. Verma AK, Verma R, Ahuja V, Paul J. Real-time analysis of gut flora in Entamoeba histolytica infected patients of Northern India. BMC Microbiol 2012; 12(1):183.
59. Sicard J-F, Le Bihan G, Vogeleer P, Jacques M, Harel J. Interactions of intestinal bacteria with components of the intestinal mucus. Front Cell Infect Microbiol 2017; 7:387.

60. Leon-Coria A, Kumar M, Chadee K. (2020). The delicate balance between Entamoeba histolytica, mucus and microbiota. Gut microbes, 11(1): 118-125.

61. Varet H, Shaulov Y, Sismeiro O, Trebicz-Geffen M, Legendre R, Coppée JY, et al. Enteric bacteria boost defences against oxidative stress in Entamoeba histolytica. Sci Rep 2018; $8(1): 1-2$.

62. Burgess SL, Buonomo E, Carey M, Cowardin C, Naylor C, Noor Z, et al. Bone marrow dendritic cells from mice with an altered microbiota provide interleukin 17A-dependent protection against Entamoeba histolytica colitis. MBio. 2014; 5(6): e01817.

63. Gilchrist CA, Petri SE, Schneider BN, Reichman DJ, Jiang $\mathrm{N}$, Begum S, et al. Role of the gut microbiota of children in diarrhea due to the protozoan parasite Entamoeba histolytica. J Inf Dis 2016; 213(10):1579-1585.

64. Sarjapuram N, Mekala N, Singh M, Tatu U. The potential of Lactobacillus casei and Entercoccus faecium combination as a preventive probiotic against Entamoeba. Probiotics Antimicrob Proteins. 2017; 9(2):142-149.

65. Lee SC, San Tang M, Lim YA, Choy SH, Kurtz ZD, Cox LM, et al. Helminth colonization is associated with increased diversity of the gut microbiota. PLoS Negl Trop Dis 2014; 8(5): e2880

66. Logan J, Navarro S, Loukas A, Giacomin P. Helminthinduced regulatory $\mathrm{T}$ cells and suppression of allergic responses. Curr Opin Immunol 2018; 54:1-6.

67. Rumyantseva T, Khayrullina G, Guschin A, Donders G. Prevalence of Ureaplasma spp. and Mycoplasma hominis in healthy women and patients with flora alterations. Diagn Microbiol Infect Dis 2019; 93: 227-231.

68. Addis MF, Rappelli P, Cappuccinelli P, Fiori PL. Extracellular release by Trichomonas vaginalis of a $\mathrm{NADP}^{+}$-dependent malic enzyme involved in pathogenicity. Microb Pathog 1997; 23(1):55-61.

69. Garber GE, Lemchuk-Favel LT, Bowie WR. Isolation of a cell-detaching factor of Trichomonas vaginalis. J Clin Microbiol 1989; 27(7):1548-1553.

70. Lehker MW, Sweeney D. Trichomonad invasion of the mucous layer requires adhesins, mucinases, and motility. Sex Trans Infect 1999; 75(4): 231-238.

71. Krieger JN, Poisson MA, Rein MF. Beta-hemolytic activity of Trichomonas vaginalis correlates with virulence. Infect Immun 1983; 41(3):1291-1295.

72. Provenzano D, Alderete JF. Analysis of human immunoglobulin-degrading cysteine proteinases of Trichomonas vaginalis. Infect Immun 1995; 63(9): 33883395.

73. Fichorova RN, Buck OR, Yamamoto HS, Fashemi $T$, Dawood HY, Fashemi B, et al. The villain team-up or how Trichomonas vaginalis and bacterial vaginosis alter innate immunity in concert. Sex Transm Infect 2013; 89: 460-466.

74. Juliano C, Cappuccinelli P, Mattana A. In vitro phagocytic interaction between Trichomonas vaginalis isolates and bacteria. Eur J Clin Microbi Infect Dis 1991; 10: 497-502. 
75. McGrory T, Meysick K, Lemchuk-Favel LT, Garber GE. The interaction of Lactobacillus acidophilus and Trichomonas vaginalis in vitro. J Parasitol 1994; 80(1):50-54.

76. Petrin D, Delgaty K, Bhatt R, Garber G. Clinical and microbiological aspects of Trichomonas vaginalis. Clin Microbiol Rev 1998; 11(2):300-317

77. Hinderfeld AS, Simoes-Barbosa A. (2020). Vaginal dysbiotic bacteria act as pathobionts of the protozoal pathogen Trichomonas vaginalis. Micro. Pathog 2020; 138:103820.

78. Fredricks DN, Fiedler TL, Marrazzo JM. Molecular identification of bacteria associated with bacterial vaginosis. N Engl J Med 2005; 353: 1899-1911.

79. Onderdonk AB, Delaney ML, Fichorova RN. The human microbiome during bacterial vaginosis. Clin Microbiol Rev 2016; 29: 223-238.

80. Ashour DS, Othman AA. Parasite-bacteria interrelationship. Parasitol Res 2020; 1-20.

81. Ajibola O, Rowan AD, Ogedengbe CO, Mshelia MB, Cabral DJ, Eze AA, et al. Urogenital schistosomiasis is associated with signatures of microbiome dysbiosis in Nigerian adolescents. Sci Rep 2019; 9(1):1-5.

82. Kay GL, Millard A, Sergeant MJ, Midzi N, Gwisai R, Mduluza T, et al. Differences in the faecal microbiome in Schistosoma haematobium infected children vs. uninfected children. PLoS Negl Trop Dis 2015; 9(6): e0003861.

83. Jenkins TP, Peachey LE, Ajami NJ, MacDonald AS, Hsieh $\mathrm{MH}$, Brindley PJ, et al. Schistosoma mansoni infection is associated with quantitative and qualitative modifications of the mammalian intestinal microbiota. Sci Rep 2018; 8:12072.

84. Cortés A, Clare S, Costain A, Almeida A, McCarthy C, Harcourt $\mathrm{K}$, et al. Baseline gut microbiota composition is associated with Schistosoma mansoni infection burden in rodent models. Front Immunol 2020; 11:593838.

85. Schneeberger PH, Coulibaly JT, Panic G, Daubenberger C, Gueuning M, Frey JE, et al. Investigations on the interplays between Schistosoma mansoni, praziquantel and the gut microbiome. Parasit Vectors 2018; 11(1):1-2.

86. Floudas A, Aviello G, Schwartz C, Jeffery IB, O'Toole PW, Fallon PG. Schistosoma mansoni worm infection regulates the intestinal microbiota and susceptibility to colitis. Infect Immun 2019; 87(8): e00275-19.

87. Elder BL, Arlian LG, Morgan MS. Sarcoptes scabiei (Acari: Sarcoptidae) mite extract modulates expression of cytokines and adhesion molecules by human dermal microvascular endothelial cells. J Med Entomol 2006; 43: 910-915.
88. Elder BL, Arlian LG, Morgan MS. Modulation of human dermal microvascular endothelial cells by Sarcoptes scabiei in combination with pro-inflammatory cytokines, histamine, and lipid-derived biologic mediators. Cytokine 2009; 47: 103-111.

89. Mullins JS, Arlian LG, Morgan MS. Extracts of Sarcoptes scabiei De Geer down-modulate secretion of IL-8 by skin keratinocytes and fibroblasts and of GM-CSF by fibroblasts in the presence of pro-inflammatory cytokines. J Med Entomol 2009; 46: 845-851.

90. Beckham SA, Boyd SE, Reynolds S, Willis C, Johnstone $\mathrm{M}$, Mika A, et al. Characterization of a serine protease homologous to house dust mite group 3 allergens from the scabies mite Sarcoptes scabiei. J Biol Chem 2009; 284(49):34413-34422.

91. Morgan MS, Arlian LG. Response of human skin equivalents to Sarcoptes scabiei. J Med Entomol 2011: 47:877-883.

92. Swe PM, Christian LD, Lu HC, Sriprakash KS, Fischer K. Complement inhibition by Sarcoptes scabiei protects Streptococcus pyogenes: An in vitro study to unravel the molecular mechanisms behind the poorly understood predilection of $S$. pyogenes to infect mite-induced skin lesions. PLoS Negl Trop Dis. 2017; 11(3): e0005437.

93. Abreu-Velez AM, Klein III AD, Howard MS. Autoreactivity to sweat glands and nerves in clinical scabies infection. $\mathrm{N}$ Am J Med Sci 2010; 2(1):42-45.

94. Carapetis JR, Connors C, Yarmirr D, Krause V, Currie BJ. Success of a scabies control program in an Australian aboriginal community. Pediatr Infect Dis J 1997; 16(5):494-499.

95. Romani L, Whitfeld MJ, Koroivueta J, Kama M, Wand H, Tikoduadua L, et al. Mass drug administration for scabies control in a population with endemic disease. N Engl J Med 2015; 373(24):2305-2313.

96. Swe PM, Zakrzewski M, Kelly A, Krause L, Fischer K. Scabies mites alter the skin microbiome and promote growth of opportunistic pathogens in a porcine model. PLoS Negl Trop Dis 2014; 8(5): e2897.

97. Cavoli G, Bono L, Tortorici C, Cavoli T L, Rotolo U. Membranous glomerulonephritis overlapping with scabies. Indian J of Nephrol 2016; 26(4): 312-313.

98. Lawrence G, Leafasia J, Sheridan J, Hills S, Wate J, Wate C, et al. Control of scabies, skin sores and haematuria in children in the Solomon Islands: another role for ivermectin. Bull World Health Organ 2005; 83(1):34-42. 